\title{
12
}

\section{Frühblüher (Mittelworträtsel)}

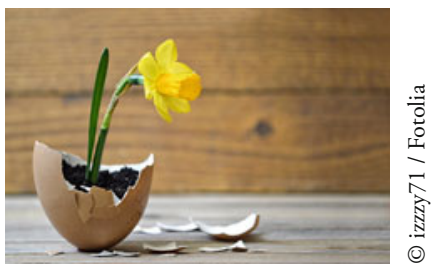

Suche in jeder Zeile das Wort, welches man links anfügen und rechts voransetzen kann, zum Beispiel FLIEDER - BUSCH - WINDRÖSCHEN (s. u.). Die Buchstaben in den neun vorgegebenen Boxen ergeben - von oben nach unten gelesen - das Lösungswort.

Tipp In jeder Zeile findet sich eine Frühblüher-Art.

\begin{tabular}{|c|c|c|}
\hline FLIEDER & $\equiv---$ & WINDRÖSCHEN \\
\hline LAUB & L_ & VEILCHEN \\
\hline WINTER & -- & TULPE \\
\hline PFERDE & - & LATTICH \\
\hline FAHRRAD & - & BLUME \\
\hline ARON & - & HOCHSPRUNG \\
\hline SAUER & & BLATT \\
\hline WASCH & & LAUCH \\
\hline TIEF & $\rightleftharpoons \ldots$ & GLÖCKCHEN \\
\hline
\end{tabular}

Lösung: 